\title{
The Effects of Caregiver Social Support and Depressive Symptoms on Child Medication Adherence and Asthma Control
}

\author{
Rachel H.F. Margolis ${ }^{1}$ (D) Sarah Dababnah ${ }^{2} \cdot$ Paul Sacco $^{2} \cdot$ Brenda Jones-Harden $^{2} \cdot$ Mary Elizabeth Bollinger $^{3} \cdot$ \\ Arlene Butz ${ }^{4}$ - Melissa H. Bellin ${ }^{2}$
}

Received: 16 February 2021 / Revised: 4 May 2021 / Accepted: 18 May 2021 / Published online: 26 May 2021

(C) W. Montague Cobb-NMA Health Institute 2021

\begin{abstract}
The purpose of this study was to examine relationships among caregiver social support, caregiver depressive symptoms, medication adherence, and asthma control in a sample of low-income, urban, Black children aged 3-12 years with uncontrolled asthma and their caregivers. Using longitudinal data from a randomized controlled trial (RCT) assessing the efficacy of an environmental control educational intervention, we used generalized estimating equations and ordered logistic regression models to evaluate the relationship between caregiver social support (Medical Outcomes Study Social Support Survey), depressive symptoms (Center for Epidemiologic Studies Depression scale), and two child asthma outcomes: (a) medication adherence (Asthma Medication Ratio) and (b) asthma control. At baseline, 45.7\% of the 208 children had very poorly controlled asthma. Nearly a third of caregivers ( $97 \%$ female) had clinically significant depressive symptoms at each data collection point. Social support was not associated with either asthma outcome nor did it moderate the relationship between depressive symptoms and child asthma outcomes. Higher caregiver depressive symptoms predicted decreased medication adherence $(b=-0.003, \mathrm{SE} 0.002)$. Moderate asthma at baseline (OR: 0.305, SE: 0.251), severe asthma at baseline (OR: 0.142, SE: 0.299), household income < \$20,000 per year (OR: 0.505, SE: 0.333), and fall season (OR: 0.643, SE: 0.215 ) were associated with poorer asthma control. Attending to the social context of low-income, urban, Black children with asthma is critical to reduce asthma morbidity. Maternal depressive symptoms are modifiable and should be targeted in interventions to improve child asthma outcomes in this vulnerable population. The RCT was registered with ClinicalTrials.gov (NCT01981564) in October 2013.
\end{abstract}

Keywords Asthma $\cdot$ Caregiver $\cdot$ Black $\cdot$ Medication adherence $\cdot$ Social support $\cdot$ Depressive symptoms

Asthma is one of the most common child health conditions in the USA, but the burden of asthma is greatest among lowincome, urban, Black children [1]. These children have higher rates of uncontrolled asthma [2], more frequent missed school days due to asthma [3], and higher healthcare utilization rates

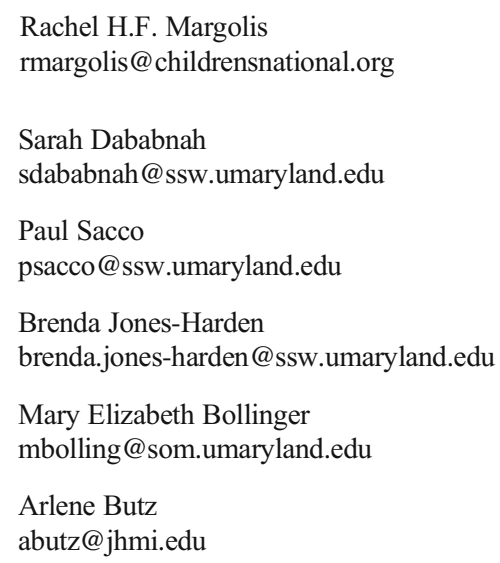

for asthma [1] and are more likely to die from the disease [1] than their economically advantaged, non-Hispanic, White peers. Accumulating evidence suggests that complex and interconnected risk factors at multiple social-ecological levels drive these disparities $[1,4]$. The disproportionate impact of

Melissa H. Bellin

mbellin@ssw.umaryland.edu

1 IMPACT DC Asthma, Center for Translational Science, Children's National Research Institute, 111 Michigan Avenue NW, Washington, DC 20010, USA

2 University of Maryland School of Social Work, 525 W. Redwood Street, Baltimore, MD 21201, USA

3 University of Maryland School of Medicine, 737 W. Lombard Street, 314, Baltimore, MD 21201, USA

4 Johns Hopkins University School of Medicine, 733 N Broadway, Baltimore, MD 21205, USA 
asthma extends to parents and caregivers who bear ultimate responsibility for disease management. Medication adherence, including daily use of long-term preventive controller medications, is particularly critical for effective asthma selfmanagement due to its relationship with better asthma control and reduced asthma morbidity and mortality [5-7].

Caregivers of youth with poorly controlled asthma may experience significant hardships due to the demands of asthma management including lost wages and benefits [8], inability to maintain stable, full-time employment [9], and psychological distress [10]. Research suggests that between 30 and $50 \%$ of mothers of low-income, urban, Black children with asthma have clinically significant symptoms of depression which persist over time [11-13]. Not only do mothers within this population experience poor quality of life as a result of clinically significant depressive symptoms [14], but these symptoms have been associated with impaired asthma management, including inconsistent adherence to child asthma medication regimens [13] and increased asthma morbidity [15].

However, less is known about protective factors (i.e., conditions that buffer against risk exposure) and resource factors (i.e., conditions that facilitate positive outcomes whether or not the individual is at risk) $[16,17]$ that may play a critical role in reducing asthma health disparities and improving asthma-related outcomes. Social support, defined as "a social network's provision of psychological and material resources intended to benefit an individual's ability to cope with stress" [18] has been positively associated with physical and psychological health across diverse populations including low-income, Black mothers [19] and mothers of children with chronic health conditions [20]. Among caregivers of low-income, urban, racial minority children with poorly controlled asthma, higher levels of social support have been linked to less depressive symptomology [12]. Social support may facilitate asthma management and control by protecting against the negative effects of caregiver depressive symptoms among low-income, minority children with asthma; however, this relationship has not been evaluated empirically. In several studies, social support was observed to have a direct effect on reduced symptom frequency, decreased functional morbidity, and better asthma control, suggesting that social support may serve as a resource factor, facilitating asthma management and control irrespective of caregiver depressive symptomology [21-23].

To address the current gaps in the literature, we utilized a risk and resilience framework to examine caregiver perceived social support as a resource factor or a protective factor on child asthma outcomes (i.e., medication adherence and asthma control) in a sample of low-income, urban, Black children with uncontrolled asthma (Fig. 1). The purpose of this study was to answer the following research questions: Do higher levels of caregiver social support [1] predict improved asthma medication adherence or asthma control over time (i.e., resource factor) and [2] moderate the relationship between caregiver depressive and asthma medication adherence or asthma control over time (i.e., protective factor)?

\section{Method}

\section{Data Source}

We used data from a randomized controlled trial (RCT) that evaluated the efficacy of an educational intervention for children with persistent asthma and frequent emergency department (ED) visits [24]. Participants were recruited from two large urban hospitals during a pediatric ED visit for treatment of an acute asthma exacerbation. Eligible children (a) were between the ages of three and 12 years, (b) had physiciandiagnosed persistent and uncontrolled asthma based on the National Asthma Education and Prevention Program (NAEPP) [5] guidelines, (c) had $\geq 2$ asthma-related ED visits or $\geq 1$ hospitalization for an asthma exacerbation during the previous 12 months, and (d) lived in the metropolitan area where the study was being conducted. Children with significant non-asthma respiratory condition (e.g., cystic fibrosis), no working phone, or foster care placement were excluded.

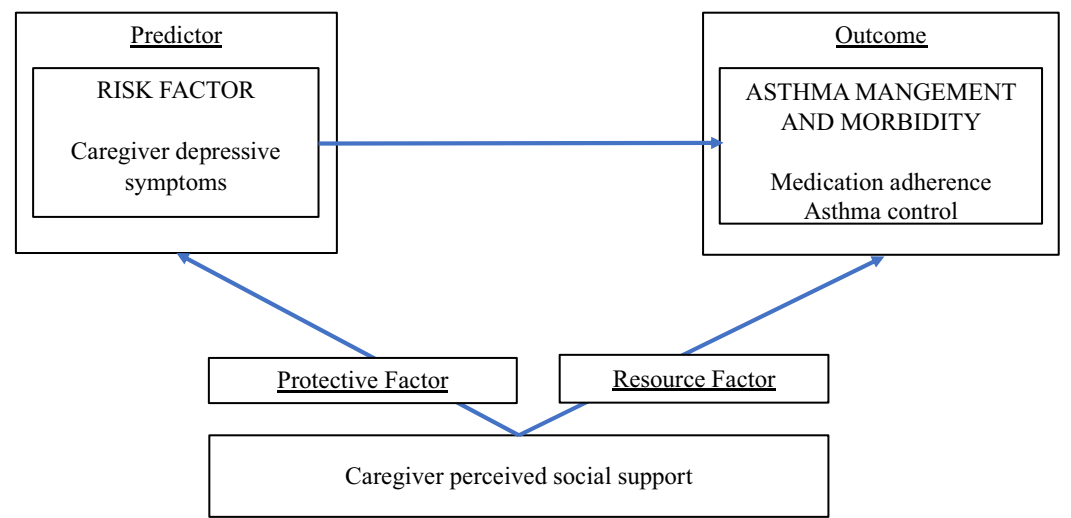

1. BASEI BASELINE CHILD CHARACTERISTICS

a. Asthma severity

b. Age

c. Gender

2. BASELINE CAREGIVER CHARACTERISTICS a. Relationship status

b. Educational level

c. Household income

3. ENVIRONMENTAL CHARACTERISTICS a. Season

Fig. 1 Conceptual model 
Enrollment occurred on a rolling basis between August 2013 and February 2016. Of the 554 children screened in the pediatric ED, 222 (40\%) enrolled in the study and were randomized to the intervention or an attention control group [24]. We restricted our analysis to Black children and their caregivers ( $N=208$ ) who comprised $93.7 \%$ of the full sample.

The institutional review boards of participating medical centers approved the RCT. Each child's caregiver gave written informed consent (and children $>8$ years of age gave verbal assent) prior to study participation, which included permission to obtain the child's pharmacy records. At baseline (T1), six (T2), and 12 (T3) months, surveys were administered in the home to each caregiver by trained research assistants. Surveys included sociodemographic and health information as well as self-reported measures of child asthma control, caregiver depressive symptoms, and caregiver-perceived social support.

Participants randomized to the intervention group received a follow-up visit with a pediatric nurse practitioner in the ED within 7 days of enrollment to evaluate asthma symptoms, provide education on guidelines-based controller and rescue medication use, and review allergen lab results [24]. In addition, the intervention group received two home visits during which a home visiting nurse trained in integrated pest management provided environmental control education and remediation based on the child's allergy testing results, as well as a brief motivational interview to instigate a total ban of smoking in the home if needed. The attention control group also received in-home services, including standard asthma education during three home visits from a community home visiting nurse, within 7 to 14 days of enrollment.

\section{Measures}

\section{Dependent Variables}

Medication Adherence Dispensing records from the past 12 months were obtained from pharmacies identified as used for asthma medication fills by the caregiver. Based on the work of Schatz et al. [25], an asthma medication ratio (AMR) was subsequently calculated by dividing the number of controller medication fills by the total asthma medication fills (i.e., controller medication and rescue medication). An AMR $\geq 0.50$ has been associated with less asthma morbidity, including better asthma control, less severe asthma symptoms, better quality of life, and fewer hospitalizations and ED visits in adults and children with asthma [25]. AMR was treated as a continuous variable.

Asthma Control As shown in Table 1, child asthma control was based on the NAEPP [5] guidelines and determined by caregiver report of (a) number of symptom days over the past 14 days, (b) number of symptom nights over the past 30
Table 1 Asthma Control Algorithm based on NAEPP-EPR3 (2007) Guidelines

\begin{tabular}{|c|c|c|c|}
\hline \multirow[b]{2}{*}{$\begin{array}{l}\text { Component of } \\
\text { asthma control }\end{array}$} & \multicolumn{3}{|c|}{ Classification of asthma control } \\
\hline & Well controlled & $\begin{array}{l}\text { Not well } \\
\text { controlled }\end{array}$ & $\begin{array}{l}\text { Very poorly } \\
\text { controlled }\end{array}$ \\
\hline $\begin{array}{r}\text { Symptom days } \\
\text { past } 2 \text { weeks }\end{array}$ & $\leq 4$ & $5-13$ & 14 \\
\hline $\begin{array}{l}\text { Symptom } \\
\text { nights past } 4 \\
\text { weeks }\end{array}$ & $0-1$ & $2-4$ & $>4$ \\
\hline $\begin{array}{l}\text { Activity } \\
\text { limitation } \\
\text { past week }\end{array}$ & $\begin{array}{l}\text { Not at all limited } \\
\text { or very slightly } \\
\text { limited }\end{array}$ & $\begin{array}{l}\text { Slightly limited, } \\
\text { moderately } \\
\text { limited, or } \\
\text { very limited }\end{array}$ & $\begin{array}{l}\text { Extremely } \\
\text { limited or } \\
\text { totally } \\
\text { limited }\end{array}$ \\
\hline $\begin{array}{l}\text { Rescue } \\
\text { medication } \\
\text { use past } 2 \\
\text { weeks }\end{array}$ & No & Yes & Yes \\
\hline $\begin{array}{l}\text { ED visit or } \\
\text { hospitaliza- } \\
\text { tion past } 12 \\
\text { months }\end{array}$ & $\begin{array}{l}\text { ED visits }=0 \text { or } \\
\text { hospitaliza- } \\
\text { tions }=0\end{array}$ & $\begin{array}{c}\text { ED visits }=1 \text { or } \\
\text { hospitaliza- } \\
\text { tions }=0-1\end{array}$ & $\begin{array}{l}\text { ED visits } \geq 2 \text { or } \\
\text { hospitaliza- } \\
\text { tions } \geq 1\end{array}$ \\
\hline $\begin{array}{l}\text { Courses of } \\
\text { OCS past } 12 \\
\text { months }\end{array}$ & $0-1$ & $\geq 2$ & $\geq 2$ \\
\hline
\end{tabular}

Note. ED emergency department, OCS oral corticosteroid

nights, (c) short-acting beta agonist (SABA) use over the past 14 days, (d) activity limitation over the past 7 days, (e) number of oral corticosteroid courses in the past year, and (f) number of asthma ED visits or hospitalizations over the past 12 months. Only children with not well-controlled or very poorly controlled asthma were eligible for study participation. Therefore, no children had well-controlled asthma at baseline.

Independent Variable: Depressive Symptoms Caregiver depressive symptoms were measured using the established 20item Center for Epidemiological Studies Depression scale (CES-D) [26]. Scores on the CES-D range from 0 to 60 . A score $\geq 16$ suggests that an individual may be at risk for clinically significant depressive symptoms [26]. The CES-D scale has been used widely with caregivers of children with asthma $[12,21]$.

Moderator: Social Support Caregiver social support was measured using an 18-item version of the Medical Outcomes Study Social Support Survey (MOS-SSS) which has been validated for use with caregivers of low-income, urban, Black children with asthma [27, 28]. Scores on the MOS-SSS range from 18 to 90 with higher scores indicating a higher level of social support. We tested the moderating effects of social support and its direct effects on each of the dependent variables. 
Covariates We included group status (i.e., intervention or control group), event time (i.e., T1, T2, and T3), and baseline child asthma severity determined by the study team according to the national guidelines [5], season, child age and sex, caregiver relationship status (partnered or not), educational level (high school graduate or not), and annual household income ( $<\$ 20,000 ; \$ 20,000$ to $\$ 39,999$; or $\geq \$ 40,000)$ as covariates in the statistical models.

\section{Data Analysis}

Missing Data Data attrition is shown in Table 2. Missing data analysis revealed that participants who were missing CES-D and MOS-SSS scores at T2 had younger children than those who had completed scores, suggesting that data were not missing completely at random. We used multiple imputation using chained equations to compute 20 imputations for the missing data on the following variables: asthma control at $\mathrm{T} 3$ and caregiver social support and depressive symptoms at $\mathrm{T} 2$ and $\mathrm{T} 3$. The final imputation regression model included all the dependent and independent variables and covariates described in the measures section with the exception of "spring" and "summer," which were eliminated due to multicollinearity. We also added caregiver age in years and sex (dummy-coded into $1=$ female and $0=$ male) to the imputation model. Several other relevant asthma morbidity variables (e.g., symptom days, symptom nights, hospitalizations) could not be added to the imputation model due to multicollinearity.

Multivariate Analysis To examine the direct (i.e., resource factor) and moderating (i.e., protective factor) effects of caregiver social support on medication adherence, we used generalized estimating equations (GEE) [29] with an unstructured correlation matrix and robust standard errors. The moderation model contained the interaction term (i.e., caregiver social

Table 2 Number of participants and percent missing data for key variables per time point

\begin{tabular}{llrr}
\hline & \multicolumn{2}{l}{$\mathrm{N}(\%$ missing $)$} \\
\cline { 2 - 4 } Variable & $\mathrm{T} 1$ & \multicolumn{1}{c}{$\mathrm{T} 2$} & \multicolumn{1}{c}{$\mathrm{T} 3$} \\
\hline CES-D & 208 & $173(16.82)$ & $136(34.62)$ \\
MOS-SSS & 208 & $176(15.4)$ & $144(30.7)$ \\
AMR $^{+}$ & 184 & -- & $182(1.1)$ \\
Asthma control & 208 & $201(3.37)$ & $154(25.97)$ \\
\hline
\end{tabular}

Note. CES - $D$ Center for Epidemiologic Studies Depression Scale, MOSSSS Medical Outcomes Study Social Support Survey, AMR Asthma Medication Ratio. ${ }^{+}$AMR collected at T1 and T3 only. Patients missing on AMR did not have any asthma medication prescriptions on file at area pharmacies which made it impossible to calculate an AMR support $\times$ caregiver depressive symptoms) and the covariates. To examine the direct and moderating effects of caregiver social support on asthma control, we used ordered logistic regression model, adjusting for clustered data and with robust standard errors [30]. Because the proportional odds assumption was met, a single odds ratio was derived across the three categories of asthma control [30]. The moderation model contained the interaction term (i.e., caregiver social support $\times$ caregiver depressive symptoms) and the covariates. In the four multivariate models, the independent variables (i.e., caregiver depressive symptoms and caregiver social support) and covariates were entered as time-varying except for baseline child asthma severity and socio-demographics. We analyzed data using Stata 14.2 [31].

\section{Results}

A slight majority of the children were male (65\%), and they had a mean age of 6.3 years $(S D=2.7)$ (Table 3$)$. Caregivers were primarily female (97\%) with a mean age of 31.5 years $(S D=7.6)$. Similar to the findings for the full study reported by Butz et al. [24], there were no statistically significant baseline differences between the intervention and control groups. Table 4 presents descriptive data for the longitudinal variables at each time point. At T1, AMR could not be calculated for 24 children, because they did not have any controller or rescue

Table 3 Participant demographics and baseline asthma morbidity $(\mathrm{N}=208)$

\begin{tabular}{ll}
\hline & M (SD) or N (\%) \\
\hline Child's age & $6.3(2.7)$ \\
Child sex (male) & $136(65 \%)$ \\
Baseline asthma severity & \\
Mild, persistent & $55(26.4 \%)$ \\
Moderate, persistent & $95(45.7 \%)$ \\
Severe, persistent & $58(27.9 \%)$ \\
Symptom days in past 2 weeks & $5.9(4.8)$ \\
Symptom nights in past 4 weeks & $7.1(8.8)$ \\
Asthma ED visits in the past 3 months (range: $0-12)$ & $1.3(1.4)$ \\
Caregiver age (range: $18-62)$ & $31.5(7.6)$ \\
Caregiver female & $202(97 \%)$ \\
Caregiver single & $156(75 \%)$ \\
Caregiver HS education or more & $168(80.8 \%)$ \\
Annual household income & \\
Very low income $(\leq \$ 19,999)$ & $95(45.7 \%)$ \\
Low income $(\$ 20,000-\$ 39,999)$ & $55(26.5 \%)$ \\
Higher income $(\geq \$ 40,000)$ & $30(14.4 \%)$ \\
\hline
\end{tabular}

Note. Percentages may not add up to 100 due to missing data. $H S$ high school 
Table 4 Longitudinal variable description by time point

\begin{tabular}{|c|c|c|c|}
\hline & \multicolumn{3}{|l|}{$\mathrm{M}(\mathrm{SD})$} \\
\hline & $\mathrm{T} 1$ & $\mathrm{~T} 2$ & $\mathrm{~T} 3$ \\
\hline MOS-SSS (range: 18-90) & $76.75(17.08)$ & $82.20(14.49)$ & $77.69(19.15)$ \\
\hline CES-D (range: 0-60) & $12.95(11.43)$ & $11.41(10.69)$ & $10.8(10.76)$ \\
\hline CES-D Score $\geq 16^{+}$ & $66(31.7)$ & $50(28.9)$ & $36(26.5)$ \\
\hline AMR (range: 0-1) & $0.43(0.26)$ & -- & $0.51(0.26)$ \\
\hline $\mathrm{AMR} \geq 0.50^{+}$ & $91(49.5)$ & -- & $109(59.9)$ \\
\hline \multicolumn{4}{|l|}{ Asthma control $^{+}$} \\
\hline Well controlled* & $0(0)$ & $25(12.0)$ & $15(7.2)$ \\
\hline Not well controlled & $93(44.7)$ & $81(38.9)$ & $78(37.5)$ \\
\hline Very poorly controlled & $115(55.3)$ & $95(45.7)$ & $61(29.3)$ \\
\hline \multicolumn{4}{|l|}{ Season $^{+}$} \\
\hline Fall & $73(35.1)$ & $46(22.1)$ & $61(29.3)$ \\
\hline Winter & $55(26.4)$ & $33(15.9)$ & $38(18.3)$ \\
\hline Spring & $44(21.2)$ & $69(33.2)$ & $32(15.4)$ \\
\hline Summer & $35(16.8)$ & $52(25.0)$ & $24(11.5)$ \\
\hline
\end{tabular}

Note. ${ }^{+} N(\%)$. ${ }^{*}$ Only children with not well-controlled or very poorly controlled asthma were eligible for study participation, and no children had well-controlled asthma at baseline. MOS-SSS Medical Outcomes Study-Social Support Scale. CES-D Centers for Epidemiologic StudiesDepression Scale. AMR Asthma Medication Ratio. Fall, September 21 to December 21. Winter, December 22 to March 21. Spring, March 21 to June 21. Summer, June 22 to September 20

medications on file at the pharmacies identified by their caregivers. Caregivers of children who did not have a baseline AMR had higher mean CES-D scores $(M=18.75)$ than caregivers of children who did have a baseline AMR $(M=12.19)$, and this difference was statistically significant [32]. The MOS-SSS demonstrated excellent internal reliability with Cronbach's alphas of $0.97,0.98$, and 0.99 at T1, T2, and T3, respectively. The CES-D demonstrated good internal reliability with Cronbach's alphas of $0.81,0.85$, and 0.87 at T1, T2, and $\mathrm{T} 3$, respectively.

\section{Multivariate Longitudinal Analyses}

GEE revealed that caregiver social support (MOS-SSS) was not a statistically significant predictor of asthma medication adherence in the unadjusted model or when the covariates were added (Table 5). In the adjusted model, caregiver depressive symptoms and event time were the only statistically significant predictors of medication adherence. For every oneunit increase on the CES-D, AMR declined by 0.003 , indicating that higher caregiver depressive symptoms were associated with lower asthma medication adherence. AMR increased four percent from $\mathrm{T} 1$ to $\mathrm{T} 3$, reflecting an improvement in asthma medication adherence over time. The interaction term testing the moderating effect of social support was not statistically significant.
Table 5 Results of GEE predicting medication adherence

\begin{tabular}{|c|c|c|c|c|}
\hline & Coeff. & SE & $95 \%$ CI lower & 95\% CI upper \\
\hline \multicolumn{5}{|c|}{ Unadjusted model } \\
\hline MOS-SSS & -0.0007 & 0.0009 & -0.002 & 0.001 \\
\hline CES-D & -0.002 & 0.002 & -0.005 & 0.0009 \\
\hline _cons & $0.466^{* * *}$ & 0.016 & 0.434 & 0.498 \\
\hline \multicolumn{5}{|c|}{ Adjusted model } \\
\hline MOS-SSS & -0.0002 & 0.0009 & -0.002 & 0.002 \\
\hline CES-D & $-0.003^{*}$ & 0.002 & -0.006 & -0.0001 \\
\hline Event time & $0.043^{* *}$ & 0.013 & 0.018 & 0.069 \\
\hline Moderate asthma & 0.00002 & 0.042 & -0.083 & 0.083 \\
\hline Severe asthma & 0.028 & 0.047 & -0.066 & 0.121 \\
\hline Child age & 0.011 & 0.006 & -0.001 & 0.023 \\
\hline Male child & -0.0005 & 0.037 & -0.073 & 0.072 \\
\hline Partnered & 0.092 & 0.053 & -0.012 & 0.196 \\
\hline HS grad & 0.008 & 0.052 & -0.094 & 0.110 \\
\hline Very low income & 0.029 & 0.050 & -0.069 & 0.128 \\
\hline Low income & -0.014 & 0.051 & -0.116 & 0.088 \\
\hline Fall & -0.006 & 0.042 & -0.089 & 0.077 \\
\hline Winter & 0.040 & 0.046 & -0.049 & 0.130 \\
\hline Intervention & -0.039 & 0.034 & -0.107 & 0.028 \\
\hline cons & $0.355^{* *}$ & 0.089 & 0.180 & 0.530 \\
\hline
\end{tabular}

Note. ${ }^{*} \mathrm{p}<0.05,{ }^{* *} \mathrm{p}<0.001 ;$ MOS-SSS Medical Outcomes Study-Social Support Scale. CES-D Centers for Epidemiologic Studies-Depression Scale

In the unadjusted model, there was a statistically significant relationship between caregiver depressive symptoms and asthma control. For every one-unit increase in CES-D (i.e., more depressive symptoms), there were three percent proportionally lower odds of asthma control. However, this effect was attenuated in the adjusted model where time was the only statistically significant predictor of better asthma control. Over time, children had $75 \%$ increased proportional odds of better asthma control. Baseline asthma severity, income, and seasonality were also statistically significant predictors of poorer asthma control (see Table 6). Severe asthma at T1 was the most robust predictor of poorer asthma control, followed by moderate baseline asthma severity (Table 6). Very low income (i.e., $<\$ 20,000$ per year) had a medium effect, while season (fall) had a small effect [33].

\section{Discussion}

In this sample of low-income caregivers of urban, Black youths with uncontrolled asthma, caregiver depressive symptoms were associated with asthma medication adherence and, to a lesser degree, child asthma control. These findings are consistent with research linking maternal depressive 
Table 6 Results of ordered logistic regression for asthma control

\begin{tabular}{llllll}
\hline & Coefficient & SE & $95 \%$ CI lower & $95 \%$ CI upper & OR \\
\hline Unadjusted model & & & & & \\
MOS-SSS & 0.002 & 0.006 & -0.009 & 0.013 & 1.002 \\
CES-D & -0.021 & 0.010 & -0.042 & -0.0008 & $0.979^{*}$ \\
Adjusted model & & & & \\
MOS-SSS & -0.006 & 0.007 & -0.019 & 0.008 & 0.994 \\
CES-D & -0.021 & 0.012 & -0.045 & 0.004 & 0.980 \\
Event time & 0.561 & 0.115 & 0.335 & 0.787 & $1.752^{* *}$ \\
Moderate asthma & -1.188 & 0.251 & -1.679 & -0.697 & $0.305^{* *}$ \\
Severe asthma & -1.949 & 0.299 & -2.535 & -1.363 & $0.142^{* *}$ \\
Child age & 0.061 & 0.042 & -0.022 & 0.144 & 1.063 \\
Male child & 0.147 & 0.212 & -0.270 & 0.563 & 1.158 \\
Partnered & -0.027 & 0.299 & -0.613 & 0.560 & 0.974 \\
HS grad & -0.448 & 0.296 & -1.028 & 0.133 & 0.639 \\
Very low income & -0.683 & 0.333 & -1.335 & -0.031 & $0.505^{*}$ \\
Low income & -0.229 & 0.358 & -0.931 & 0.473 & 0.795 \\
Fall & -0.441 & 0.215 & -0.863 & -0.020 & $0.643^{*}$ \\
Winter & -0.329 & 0.239 & -0.797 & 0.139 & 0.720 \\
Intervention & 0.152 & 0.209 & -0.258 & 0.561 & 1.164 \\
\hline
\end{tabular}

Note. ${ }^{*} \mathrm{p}<0.05,{ }^{* *} \mathrm{p}<0.001 ;$ MOS-SSS Medical Outcomes Study-Social Support Scale. CES-D Centers for Epidemiologic Studies-Depression Scale symptoms to suboptimal management of child asthma medication regimens among low-income, urban, Black children with asthma including (a) primary medication nonadherence (i.e., failure to fill a new prescription) [32], (b) daily controller medication nonadherence [13], and (c) reliance on quick-relief/rescue medications [34]. Maternal depressive symptoms have also been associated with other aspects of asthma management, including higher rates of asthma-related ED visits [11], asthma-related unscheduled clinic visits, and hospitalizations [35]. Our findings highlight the need for healthcare providers to understand the social context of children with asthma and to provide appropriate family supports, including assessment and monitoring of caregiver depressive symptoms and linkage to mental health resources [4, 36]. Many brief, validated tools for screening depressive symptoms are available, including a twoitem version of the Patient Health Questionnaire [37]. Stepped care approaches for identifying and managing maternal depression in pediatric settings have been welldescribed in the literature on postpartum depression and may provide a useful framework for addressing depressive symptoms among asthma caregivers [38]. Telehealth, which has expanded dramatically during the COVID-19 pandemic, may facilitate access to mental health services for identified caregivers and is an important area of future investigation [39].

Baseline asthma severity was the strongest predictor of poor asthma control over time, which further underscores the importance of providers engaging families of youths with higher disease severity for intervention. Because an annual income less than $\$ 20,000$ was also associated with poorer asthma control, healthcare providers should be aware that poverty not only contributes to poor asthma outcomes, but it also disproportionally affects Black children [4]. Furthermore, structural racism has been-and continues to be-a major driver of economic disadvantage in Black communities that needs to be addressed on a policy level [4]. Children living in low-income neighborhoods have increased exposure to indoor allergens and second-hand tobacco smoke combined with insufficient financial resources to implement the home environmental controls needed to mitigate that exposure [9, 40]. Finally, season (fall) also predicted poorer asthma control, reflecting a known seasonal pattern of increased asthma exacerbations and hospitalizations associated with increased viral exposure when school starts, fall allergen exposures, and low controller medication fills in late summer [41].

We were surprised that caregiver social support had neither a significant direct (i.e., resource factor) nor indirect (i.e., protective factor) effect on child asthma outcomes. Our results could reflect the optimal matching hypothesis [42], suggesting that social support is most effective when it is tailored to meet the needs imposed by a specific source of stress. Indeed, it is possible that specific supports related to asthma caregiving may be required to improve caregiver well-being and, in turn, child asthma outcomes. Two interventions that included components providing targeted asthma-caregiving support 
showed reduced symptom frequency [23] and better asthma control [22] in similar samples of children with asthma and their caregivers. A general measure of social support, such as the MOS-SSS used in this study, might not be able to capture the specific supports that provide an optimal match. Bellin et al. [43] reported similar results, finding general social support measured by the MOS-SSS did not buffer the negative effects of asthma management stress on caregiver quality of life in a longitudinal study within a similar population of asthma caregivers. Therefore, future research is needed to develop and test social support measures that match the specific needs associated with asthma caregiving, especially among caregivers of low-income, urban, Black children with poorly controlled asthma. Furthermore, while several interventions that provided targeted material, informational, and emotional support related to asthma management have demonstrated direct effects on reduced symptom frequency [23] and better asthma control [22], more research is needed to identify and assess interventions that precisely target the specific needs of caregivers related to management of their child's asthma.

Given the dearth of literature on the moderating effect of social support (general or asthma related) on the relationship between caregiver depressive symptoms and any child asthma outcome, future studies are needed to examine social support as a protective factor. Research investigating the possible moderating effect of caregiver social support on the relationship between caregiver depressive symptoms and (a) asthmarelated emergency healthcare utilization and (b) asthma symptoms may be particularly fruitful given a growing body of research linking caregiver depression to these specific asthma outcomes $[11,35,44]$. Investigation of other possible protective factors - including religiosity, self-efficacy, and coping skills, among others - may be warranted as well [19, 45].

Notably, medication adherence and asthma control improved over time for participants in both the intervention and attention control groups. This finding suggests that the provision of services in the home to all caregivers and children may have played a role in improving these outcomes. Indeed, while the Asthma Express intervention was distinct from the Attention Control services, both groups received some form of in-home asthma education from a nurse. Several other interventions that provided in-home services have demonstrated positive outcomes [23, 46, 47]. For example, among children 3 to 13 years with poorly controlled asthma, Krieger et al. [23] found that those in the social support intervention groupwhich involved asthma education from a community health worker (CHW) during home visits - had nearly 25 more symptom-free days per year than the those in the control group who did not receive any in-home services. Parker et al. [46] implemented a year-long intervention that consisted of multiple CHW home visits to 298 urban, racial, and ethnic minority children aged 7 to 11 years with persistent asthma. Among several other positive outcomes, the intervention effectively reduced the proportion of children reporting inadequate use of asthma controller medication and the proportion of caregivers reporting depressive symptoms. Future research should investigate what specific components of these types of interventions mediate improvements in asthma outcomes for children (e.g., social support, self-efficacy, information/education, relationship/therapeutic alliance with the interventionist) and the relationship between intervention setting (e.g., home, hospital, clinic) and efficacy. In the context of the COVID-19 pandemic, examining the role of telehealth and other digital interventions may be particularly relevant as a means of increasing access to psychosocial support for children with asthma and their caregivers [48].

This study has several strengths including the focus on a high-risk population and the use of longitudinal data. Another strength was the use of pharmacy records to calculate AMR. There are limitations to this study as well. First, besides AMR, variables were measured by caregiver self-report, which introduces recall, social desirability, and common method bias. Although AMR was calculated based on pharmacy records, the pharmacies were identified by caregiver report. Future studies should use a combination of measurement methods (e.g., caregiver report, healthcare provider report, child report, medical records) in order to reduce the aforementioned biases. Second, although child age was not significant, the ages of children included in the study ( 3 to 12 years) encompass a wide range of development. Different developmental phases require contrasting levels of parental involvement and parenting strategies, which may have an impact on medication adherence and asthma control. Future studies should explore the relationship between child development/parenting and asthma outcomes. Third, nearly $12 \%$ of the sample (24/208) could not be included in the GEE predicting AMR because these children did not have any controller or rescue medications on file at the pharmacies identified by their caregivers. Caregivers of these children had higher mean scores on the CES-D $(p=0.03)$, suggesting that caregiver depression may have been a factor in the caregiver not filling prescriptions for the child's asthma medications (i.e., primary medication nonadherence). Margolis et al. [32] identified caregiver depressive symptoms as a predictor of primary medication nonadherence in a separate multivariate analysis. Finally, the results of this analysis of a specific population might not be generalizable to other populations of children with asthma and their caregivers.

Despite these limitations, the results of this study demonstrate that although non-modifiable factors (i.e., season) and entrenched structural factors (i.e., economic disadvantage) appear to have the largest effect on select asthma outcomes among low-income, urban, Black children with persistent and uncontrolled asthma, other potentially modifiable factors might be areas for future intervention. Specifically, this study found that maternal depressive symptoms play a role in asthma medication adherence, which healthcare providers can 
target to improve asthma care and outcomes for these children and their caregivers. Finally, although we did not find that social support was a resource or protective factor in this study, we note that only a very small body of literature has examined the direct effect of caregiver social support on child asthma morbidity. Moreover, no other study has examined the moderating effect of social support (general or asthma related) on the relationship between caregiver depressive symptoms and any child asthma outcome. Further investigation of the relationships between caregiver social support, caregiver depressive symptoms, and child asthma outcomes among low-income, urban, Black families is needed to inform efforts to improve asthma healthcare and well-being for this high-risk population.

\section{Availability of Data and Material Not applicable.}

Code Availability Not applicable.

Author Contribution Dr. Margolis conceptualized and designed the study, carried out the analyses, drafted the initial manuscript, and reviewed and revised the manuscript. Drs. Bellin, Dababnah, Sacco, Jones Harden, and Bollinger conceptualized and designed the study and reviewed and revised the manuscript. Dr. Butz conceptualized and designed the larger clinical investigation from which this study is drawn. She also reviewed and revised the manuscript. All authors approved the final manuscript as submitted and agreed to be accountable for all aspects of the work.

Funding This study was supported by grant NR013486 from the National Institute of Nursing Research, National Institutes of Health.

\section{Declarations}

Ethics Approval All procedures performed in studies involving human participants were in accordance with the ethical standards of the institutional and/or national research committee and with the 1964 Helsinki Declaration and its later amendments or comparable ethical standards. The study was approved by the Johns Hopkins Medical and the University of Maryland Institutional Review Boards.

Consent to Participate Each child's caregiver gave written informed consent (and children $>8$ years of age gave verbal assent) prior to participation in the study.

Consent for Publication Not applicable.

Conflict of Interest The authors declare no competing interests.

\section{References}

1. Stempel H, Federico MJ, Szefler SJ. Applying a biopsychosocial model to inner city asthma: recent approaches to address pediatric asthma health disparities. Paediatr Respir Rev. 2019 Jan;1.

2. Centers for Disease Control. Uncontrolled asthma among children, 2012-2014 [Internet]. Centers for Disease Control; 2019 Jul [cited
2019 Oct 2]. Available from: https://www.cdc.gov/asthma/asthma stats/uncontrolled-asthma-children.htm

3. Hsu J, Qin X, Beavers SF, Mirabelli MC. Asthma-related school absenteeism, morbidity, and modifiable factors. Am J Prev Med. 2016 Jul 1;51(1):23-32.

4. Williams DR, Sternthal M, Wright RJ. Social determinants: taking the social context of asthma seriously. Pediatrics. 2009 Mar;123(Suppl 3):S174-84.

5. National Asthma Education and Prevention Program. Expert Panel Report 3: Guidelines for the Diagnosis and Management of Asthma. National Heart, Lung, and Blood Institute (US); 2007.

6. Desai M, Oppenheimer JJ. Medication adherence in the asthmatic child and adolescent. Curr Allergy Asthma Rep. 2011 Dec;11(6): 454-64.

7. Engelkes M, Janssens HM, de Jongste JC, Sturkenboom MCJM, Verhamme KMC. Medication adherence and the risk of severe asthma exacerbations: a systematic review. Eur Respir J. 2015 Feb;45(2):396-407.

8. Schmier JK, Manjunath R, Halpern MT, Jones ML, Thompson K, Diette GB. The impact of inadequately controlled asthma in urban children on quality of life and productivity. Ann Allergy Asthma Immunol. 2007 Jan 1;98(3):245-51.

9. Bellin MH, Newsome A, Lewis-Land C, Kub J, Mudd SS, Margolis R, et al. Improving care of inner-city children with poorly controlled asthma: what mothers want you to know. J Pediatr Health Care. 2018 Jul 1;32(4):387-98.

10. Bellin MH, Collins KS, Osteen P, Kub J, Bollinger ME, Newsome A, et al. Characterization of stress in low-income, inner-city mothers of children with poorly controlled asthma. J Urban Health. 2017 Dec;94(6):814-23.

11. Bartlett SJ, Kolodner K, Butz AM, Eggleston P, Malveaux FJ, Rand CS. Maternal depressive symptoms and emergency department use among inner-city children with asthma. Arch Pediatr Adolesc Med. 2001 Mar;155(3):347-53.

12. Kub J, Bellin MH, Butz A, Elizabeth Bollinger M, Lewis-Land C, Osteen P. The chronicity of depressive symptoms in mothers of children with asthma. J Nurs Res. 2018;40(11):1581-97.

13. Margolis RHF, Bellin MH, Tsoukleris M, Unick J, Kub J, Butz AM. The relationship between caregiver depressive symptoms and child asthma medication adherence: a multilevel analysis. Soc Work Res. in press.

14. Ekim A, Ocakci AF. Caregiver burden in pediatric asthma: a systematic review. Health Sci J [Internet]. 2017;10(6) http://www.hsj. gr/medicine/caregiver-burden-in-pediatric-asthma-a-systematicreview.php?aid=17871.

15. Wood BL, Brown ES, Lehman HK, Khan DA, Lee MJ, Miller BD. The effects of caregiver depression on childhood asthma: pathways and mechanisms. Ann Allergy Asthma Immunol. 2018 Oct 1;121(4):421-7.

16. Bellin M, Osteen P, Collins K, Butz A, Land C, Kub J. The influence of community violence and protective factors on asthma morbidity and healthcare utilization in high-risk children. J Urban Health. 2014 Aug;91(4):677-89.

17. Koinis-Mitchell D, McQuaid EL, Jandasek B, Kopel SJ, Seifer R, Klein RB, et al. Identifying individual, cultural and asthma-related risk and protective factors associated with resilient asthma outcomes in urban children and families. J Pediatr Psychol. 2012 May;37(4):425-37.

18. Cohen S. Social relationships and health. Am Psychol. 2004 Nov;59(8):676-84.

19. Siefert K, Finlayson TL, Williams DR, Delva J, Ismail AI. Modifiable risk and protective factors for depressive symptoms in low-income African American mothers. Am J Orthopsychiatry. 2007 Jan;77(1):113-23. 
20. Dewey D, Crawford SG. Correlates of maternal and paternal adjustment to chronic childhood disease. J Clin Psychol Med Settings. 2007 Sep;14(3):219-26.

21. Clawson AH, Borrelli B, McQuaid EL, Dunsiger S. The role of caregiver social support, depressed mood, and perceived stress in changes in pediatric secondhand smoke exposure and asthma functional morbidity following an asthma exacerbation. Health Psychol. 2016 Jun;35(6):541-51.

22. Gustafson D, Wise M, Bhattacharya A, Pulvermacher A, Shanovich K, Phillips B, et al. The effects of combining Webbased eHealth with telephone nurse case management for pediatric asthma control: a randomized controlled trial. J Med Internet Res. $2012 \mathrm{Jul} ; 14(4): \mathrm{e} 101$.

23. Krieger J, Takaro TK, Song L, Beaudet N, Edwards K. A randomized controlled trial of asthma self-management support comparing clinic-based nurses and in-home community health workers: the Seattle-King County Healthy Homes II Project. Arch Pediatr Adolesc Med. 2009 Feb;163(2):141-9.

24. Butz AM, Bollinger ME, Ogborn J, Morphew T, Mudd SS, Kub JE, et al. Children with poorly controlled asthma: randomized controlled trial of a home-based environmental control intervention. Pediatr Pulmonol. 2019 Mar;54(3):245-56.

25. Schatz M, Zeiger RS, Vollmer WM, Mosen D, Mendoza G, Apter $\mathrm{AJ}$, et al. The controller-to-total asthma medication ratio is associated with patient-centered as well as utilization outcomes. Chest. 2006 Jul 1;130(1):43-50.

26. Radloff LS. The CES-D Scale: A self-report depression scale for research in the general population. Appl Psychol Meas. 1977 Sum;1(3):385-401.

27. Sherbourne CD, Stewart AL. The MOS social support survey. Soc Sci Med. 1991 Mar 15;32(6):705-14.

28. Margolis R, Bellin MH, Sacco P, Harrington D, Butz A. Evaluation of MOS social support in low-income caregivers of African American children with poorly controlled asthma. J Asthma. 2018;1:1-8.

29. Liang K-Y, Zeger SL. Longitudinal data analysis using generalized linear models. Biometrika. 1986;73(1):13-22.

30. Fullerton AS. A conceptual framework for ordered logistic regression models. Sociol Methods Res. 2009 Nov;38(2):306-47.

31. StataCorp. Stata Statistical Software: Release 14. College Station, TX: StataCorp; 2015.

32. Margolis RHF, Bellin M, Morphew T, Tsoukleris M, Bollinger ME. Butz, Arlene. Caregiver depressive symptoms and primary medication nonadherence in children with asthma. J Pediatr Health Care. (in press).

33. Olivier J, May WL, Bell ML. Relative effect sizes for measures of risk. Communications in statistics: theory \& methods. 2017 Jul 15;46(14):6774-81.

34. Kub J, Jennings JM, Donithan M, Walker JM, Land CL, Butz A. Life events, chronic stressors, and depressive symptoms in lowincome urban mothers with asthmatic children. Public Health Nurs. 2009 Jul;26(4):297-306.

35. Brown ES, Gan V, Jeffress J, Mullen-Gingrich K, Khan DA, Wood $\mathrm{BL}$, et al. Psychiatric symptomatology and disorders in caregivers of children with asthma. Pediatrics. 2006 Dec;118(6):e1715-20.
36. National Academies of Sciences, Engineering, and Medicine. Integrating social care into the delivery of health care: moving upstream to improve the nation's health [Internet]. Washington, D.C.: National Academies Press; 2019 [cited 2020 Jan 23]. Available from: https://www.nap.edu/catalog/25467

37. El-Den S, Chen TF, Gan Y-L, Wong E, O'Reilly CL. The psychometric properties of depression screening tools in primary healthcare settings: a systematic review. J Affect Disord. 2018 Jan;225:503-22.

38. Olin SS, McCord M, Stein REK, Kerker BD, Weiss D, Hoagwood $\mathrm{KE}$, et al. Beyond screening: a stepped care pathway for managing postpartum depression in pediatric settings. J Women's Health. 2017 Sep;26(9):966-75.

39. Badawy SM, Radovic A. Digital approaches to remote pediatric health care delivery during the COVID-19 pandemic: existing evidence and a call for further research. JMIR Pediatr Parent. 2020 Jun 25;3(1):e20049.

40. Bellin MH, Land C, Newsome A, Kub J, Mudd SS, Bollinger ME, et al. Caregiver perception of asthma management of children in the context of poverty. The Journal Of Asthma: Official Journal Of The Association For The Care Of Asthma. 2017 Mar;54(2):162-72.

41. Johnston NW, Johnston SL, Duncan JM, Greene JM, Kebadze T, Keith PK, et al. The September epidemic of asthma exacerbations in children: a search for etiology. J Allergy Clin Immunol. 2005 Jan;115(1):132-8.

42. Cutrona CE, Russell DW. Type of social support and specific stress. In: Social support: An interactional view. 1990. p. 319-66.

43. Bellin MH, Osteen P, Kub J, Bollinger ME, Tsoukleris M, Chaikind L, et al. Stress and quality of life in urban caregivers of children with poorly controlled asthma: a longitudinal analysis. J Pediatr Health Care. 2015 Dec;29(6):536-46.

44. Otsuki M, Eakin MN, Arceneaux LL, Rand CS, Butz AM, Riekert KA. Prospective relationship between maternal depressive symptoms and asthma morbidity among inner-city African American children. J Pediatr Psychol. 2010 Aug;35(7):758-67.

45. Southwick SM, Charney DS. The science of resilience: implications for the prevention and treatment of depression. Science. 2012 Oct 5;338(6103):79-82.

46. Parker EA, Israel BA, Robins TG, Mentz G, Lin X, BrakefieldCaldwell W, et al. Evaluation of community action against asthma: a community health worker intervention to improve children's asthma-related health by reducing household environmental triggers for asthma. Health Educ Behav. 2008 Jun;35(3):376-95.

47. Weinstein SM, Pugach O, Rosales G, Mosnaim GS, Orozco K, Pappalardo AA, et al. Psychosocial moderators and outcomes of a randomized effectiveness trial for child asthma. J Pediatr Psychol. 2021:jsab011.

48. Serlachius A, Badawy SM, Thabrew H. Psychosocial challenges and opportunities for youth with chronic health conditions during the COVID-19 pandemic. JMIR Pediatr Parent. 2020 Oct 12;3(2): e23057.

Publisher's Note Springer Nature remains neutral with regard to jurisdictional claims in published maps and institutional affiliations. 